\title{
INVESTIGAÇÃO SOBRE A PRESENÇA DE LEPTOSPIRAS NOS OVÁRIOS DE HAMSTERS EXPERIMENTALMENTE INFECTADOS COM Leptospiras interrogans SOROTIPO POMONA*
}

\author{
INVESTIGATION ON THE PRESENCE OF LEPTOSPIRES IN OVARIES OF HAMSTERS \\ EXPERIMENTALLY INFECTED WHITH Leptospiras interrogans SEROVAR POMONA
}

Claudio Roberto de Almeida CAMARGO'; Silvlo Arruda VASCONCELI.OS'; Rodolfo NÜRMHERGER JUNIOR'; Estevão de Camargo PASSOS“; Zenaide Maria de MORAIS"; José Antonio VISINTIN

\begin{abstract}
RESUMO
De 90 hamsters primíparas com 80 a 120 gramas de peso vivo, 75 foram inoculadas com a dose individual de $0,5 \mathrm{ml}$ de estirpe virulenta do sorotipo pomona (30 a 40 leptospiras ativas por campo microscópico, no aumento de 200 vezes) e as 15 remanescentes constituíram o grupo testemunho næ̌o infectado. Todos os animais tratados com leptospiras apresentaram os sinais da infeç̧ăo (prostração, taquipnéia, eriçamento do pelame, icterícia e hemorragias nasal, bucal e perincal) e foram sacrificados por ocasiào da fase agônica da doença, situada entre o quarto e o sćtimo dia da inoculaçăo. Nesta oportunidade, os ovários foram colhidos $\mathrm{cm}$ condiçðes assépticas e submetidos à técnica de visualização de leptospiras (exame direto em microscopia de campo escuro, coloração argêntica de Levaditi e reação de imunofluorescência direta), cultivo em meio de Fletcher e exame histopatológico (coloração de hematoxilina e eosina). A ocorrência de uma possível contaminação estabelecida durante a retirada dos ovários foi investigada através da lavagem em solução saliná tamponada estéril. As leptospiras foram demonstradas $\mathrm{cm}$ todos os ovários do grupo de animais experimentalmente inoculados (lavados e não lavados), através da coloração de Levadiu, reação imunofluorescência direta e também no cultivo em meio de Fletcher. O exame direto em microscopia de campo escuro mostrou ser uma técnica muito pouco sensivel. O exame das preparaçoes submetidas à coloraçăo argênuca possibilitou a visualizaçāo de leptospiras em diferentes estruturas dos ovários, incluindo: o interstício, a zona pelúcida e o interior dos óvulos. Os exames histopatológicos permitiram observar as alteraçðes morfológicas lípicas de um processo inflamatório agudo em $57 \%$ dos ovários examinados.
\end{abstract}

UNITERMOS: Leptospirose; Leptospira interrogans, isolamento; Ovários, hamster

\section{INTRODUÇĀO}

A leptospirose tem como principal mecanismo de contágio a exposição à água ou solo contaminado (BLOOD et al.'. 1983); no entanto a sua transmissão venérea já foi amplamente confirmada tanto na monta natural como na inseminaçăo artificial (SLEIGHT; WILLIAMS ${ }^{24}, 1961$; KIKTENKO et al. ${ }^{13}$, 1976).

A presença de leptospiras na uretra de doadores de sêmen infectados ressalta a importância do controle sanitário de tais animais (SLEIGHT: WILLIAMS ${ }^{24}, 1961$ ); entretanto o crescente desenvolvimento dos procedimentos de transferência de embrioes (MARPLETOFT's ${ }^{\prime}$ 1986) tem despertado a preocupaçæo para a possivel existência de leptospiras em estruturas do aparelho reprodutor das fêmeas dos animais domésticos.

SANGER et al."' (1961) relataram a presença de pequena quantidade de leptospiras nos ovários e na parede uterina de hamsters experimentalmente infectados com L. interrogans sorotipo pomona, porém, nesta oportunidade, não houve a preocupação com a verificação da estrutura do órgão envolvido, bem como se o microrganismo observado poderia ser consequência de uma contaminaçăo externa estabelecida durante a colheita do material.

ELLIS; THIERMAN ${ }^{10}$ (1986) isolaram L. interrogans sorotipo hardjo do útero e oviduto de vacas năo prenhes. ELLIS el al.9 (1986) relataram o isolamento do sorotipo australis do útero e ovidutos de porcas com histórico de abortamento.

CHEN SHISONG; WRATHALL? (1989) divulgaram uma microfotografia eletrônica obtida por Bailey, na qual é apresentada a L. interrogans sorotipo bratislava, aderida à zona pelúcida de um embriāo de suíno. Estes autores referiram que o microrganismo não foi removido mesmo após a realização de dez lavagens sucessivas.

1-Pesquisador Cienúfico - Instututo Butanta

2-Professor Associado - Faculdade de Medicina Velerintria e Toolecnia da USP

3-Professor Doutor - Faculdade de Medicina Veterinfíria e Zootecnia da USP

4-Pesquisador Científico - Instituto Biológico

5-Biologa - Faculdade de Medicina Vecerinária e Zootecnia da USP

- Dissernaça de Mestrado apresentada a Faculdade de Medicina Veterinária e Zoolecnia da Universidade de Sto Paulo. Trabalho conduzido com o apoio da FAPESP. Processo 90/0267-3. 
Tendo em vista a imporância da obtençð̊o de maiores conhecimentos sobre as doenças transmitidas pelos materiais de muluplicação animal, foi delineado o presente estudo que teve por objetivo investigar a presença de leptospiras e de alteraçðes histológicas nos ovários de hamsters sacrificados durante a fase agónica da leptospirose experimentalmente induzida pela inoculaçăo de L. interrogans sorotipo pomona.

\section{MATERIAL E MÉTODO}

Foram utilizadas 9 ) hamsters" (Mesocricetus auratus) fermcas primiparas, com 80 a 120 gramas de peso vivo, clinicamente sadias, mantidas em infoctónio com temperaura ambiental nảo climatizada, no interior de caixas plásticas, forradas com maravalha esterilizada, trocada diariamente, recebendo água comum da rede pública e raç̆o concercial peletizada "ad libitum".

O inoculum foi representado por estirpe de L. interrogans sorotipo pomona ${ }^{\circ}$, tipificada pela prova de absorçăo de aglutininas (SANTA ROSA ${ }^{20}, 1970$ ), cuja virulência foi preservada auravés da armazcnagem $\mathrm{cm}$ nitrogênio liquido (ALEXANDER et al. ${ }^{2}, 1972$ ). $\mathrm{cm}$ ampolas contendo $85 \%$ de cultura com 10 dias de crescimento em meio líquido, $5 \%$ de glicerina neutra estéril c 10\% de soro estéril de coelho, inativado a $56^{\circ} \mathrm{C}$ positivos por 40 minutos. $O$ conteúdo de tais ampolas foi semeado em tubos com o meio semi-sólido de Fletcher, que foram incubados à temperatura de $28^{\circ} \mathrm{C}$ positivos durante 10 dias. Nesta ocasiăo, as culturas foram examinadas em microscopia de campo escuro a fim de serem confimadas as características de riqueza, motilidade e ausência de contaminantes. As amostras utilizadas apresentavam de 30 a 40 leptospiras ativas por caunpo microscópico no aumento de 200 vezes. Cada animal recebeu 0.5 mililitro deste inoculum via intraperitoncal.

O meio de cultura utilizado para isolamento e preparo do inoculum foi o meio semi-sólido de Fletcher, enriquecick com $10 \%$ de soro estéril de coelho, inativado à temperatura de $56^{\circ} \mathrm{C}$ positivos por 40 minutos. O meio completo foi inativado a $56^{\circ} \mathrm{C}$ positivos por 40 minutos e submetido aos controles de esterilidade e de crescimento (SANTA ROSA ${ }^{20}, 1970$ ).

O diluente para o preparo das suspensoes de tecido ovariano foi representado pela soluçåo salina tamponada com o tampăo fosfatado de Sorensen, preparada como preconizado por SANTA ROSA ${ }^{20}$ (1970).

O fixador para técnicas histopatológicas foi a solução aquosa de formol diluida a $10 \%$.

A técnica de isolamento de leptospira em meio de cultura foi o procedimento das diluiçoes seriadas proposto por FAINE" (1982), com as seguintes particularidades: as suspensðes do tecido ovariano, preparadas assepticamente em soluçăo salina Lamponada de Sorensen, foram examinadas nas concentraçocs de 10,0;1,0 c 0,1\% (peso/volume); o volume de inoculum por tubo de meio de cultura foi o de $0,1 \mathrm{ml}$; foram utilizados dois tubos de meio de cultura para cada concentração de tecido; os tubos scmeados foram incubados à temperatura de $28^{\circ} \mathrm{C}$ positivos. A verificaça do crescimento de leptospiras foi efelivada pelo exame dos culuvos em microscopia de campo escuro no terceiro, sexto e décimo dia de incxulaçào.

A técnica de Levaditi para a evidenciaçăo de lepwspiras em cortes de tecido foi execulada conforme o procedimento descrito por McMANUS; MOWRY ${ }^{14}$ (1965). O exame das preparaçzos foi realizado em microscópio de luz ópticae com ocular 10 e objetivas 40 e $1(0)$ (imersao) com o condensador de campo claro.

O exame direto das suspensodes de tecido ovariano em microscopia de campo escuro foi realizado em microscópio de luz optica' com ocular 10, objetiva 40 e condensador de campo escuro de imersão.

A técnica de coloraça pela hematoxilina - cosina foi executada scgundo o procedimento preconizado por BEHMER et al." (1976), para coloraçào de matcriais fixados em formol, incluídos cm blocos de parafina e cortados em micrótomo.

A reação de imunofluorescência direta foi realizada cm decalques de tecido ovariano, preparados através da compresião do órgåo cm lâmninas de microscopia do tpo extra finaz. Toxdos os demais procedimentos foram executados conforme a técnica descrila por PASSOS el al. ${ }^{17}$ (1988). As lcituras foram realizadas em microscópio de luz ulera-violela' com ocular 10, objelı. va de imersao plana e condensador campo excuro de imersáo.

O conjugado anti L. interrogans sorolipo pomona foi prouju zido com amostra homóloga à utilizada para a infecçăo experimental apresentindo a diluiçào ótima de trabalho de $1: 40$.

Os 90 (noventi) hamsters utilizados foram subdivididos em 18 grupes experimentais com cinco individuos cada, constıte idos com base no princípio da homogeneizaçăo na variação do peso vivo dos seus componentes. Quinze grupos foran utulizados para as incxulaçoes experimentais e os uês rema nescentes nāo receberam nenhum tipo de inoculaçððo, servindo como controles.

As inoculaçðes foram iniciadas após um periodo de adłaptaçăo com 15 dias de duraçå. A conduçæo do experimento contemplou a ulilizaçăo de um grupo experimental por sernana.

Os animais inoculados foram observados a cada 12 (doze) horas, atentando-se para a presença dos sinais clínicos descrilos por PASSOS ei al. " (1988).

A cutanásia foi excculada quando os hamsters encontravamse na fase agônica da doença, utilizando-se para tanto uma câmara com vapores de clorofórmio.

A extraçào dos ovários foi realizada imediatamente após o sacrificio, tomando-se os cuidados. usuais de assepsia (PASSOS et al. $\left.{ }^{17} 1988\right)$.

a = Fomecidos pelo Biotério do Departameito de Patologia da liaculdade de Medicına Vetennána e Tocueconia da Universadade de Sào Paulo; b = Obudo junto a Salsbury Laboralório Lida; $c=$ Difco; $d=$ Merck; $c=$ Carl Zeıss; $f=$ Wild - M-20; $8=$ Perfecta; $h=$ Carl Zeiss; $1=$ Laboratóno de Toonoses Bactenanas da Faculdade de Medicina Vecennéria e Zootecria da Universidade de Sto Paulo. 
O processamento dos ovários dos cinco componentes de cada grupo experimentalmente inoculado adotou a seguinte conduta: os ovários de duas fêmeas foram destinados à técnica de isolamento de leptospiras por cultivo, sendo um dos pares de órgåos submetido a uma lavagem pré-cultivo com 10 minutos de duraç̊o e três trocas de soluçăo salina tamponada estéril; para os outros três representantes do grupo, a análise do efeito da lavagem foi obuida a partir dos órgãos colhidos de um mesmo animal, aplicando-se tal procedimento apenas para o ovário direito.

Para cada conjunto de materiais provenientes de cinco hamsters experimentalmente infectados com $\mathbf{L}$. interrogans sorotipo pomona, foram incluídos os ovários provenientes de um animal do grupo controle năo infectado, destinado à técnica de coloraçæo pela hematoxilina-eosina.

A análise dos resultados obtidos empregou os testes não paramétricos de Qui Quadrado e Mc Nemar, (SIEGEL ${ }^{23}, 1981$ ). O nível de significância adotado foi o de 0,05 .

\section{RESULTADOS}

Os 75 hamsters experimentalmente inoculados com a estipe virulenta de $\mathbf{L}$. interrogans sorotipo pomona, manifestaram os sinais clínicos da doença (prostraçăo, taquipnéia, eriçamento do pelame, icterícia e hemorragias localizadas no focinho e na região perineal) e foram sacrificados por ocasiåo do quanto ao sétimo dia pós-inoculação (estágio agônico). A necrópsia de tais animais possibilitou a evidenciaçăo de alteraçōes macroscópicas caracterizadas por: a) hemorragias nos rins, ovários e pulmóes; b) hipertrofia e congestăo do fígado e baço; c) icterícia do tecido subculâneo e das mucosas.

Os 15 animais do grupo controle não demonstraram qualquer alteração de saúde e quando necropsiados năo foi evidenciada qualquer alteração macroscópica.

Na Tab.1 são apresentados os resultados dos cultivos em meio de Fletcher dos ovários de 30 animais experimentalmente inoculados com L. interrogans sorotipo pomona, segundo a natureza do resultado obtido, o momento da realização do exame e a condiça de lavagem prévia do órgà. A observaça dos valores apresentados nesta tabela revela que no décimo dia de cultivo foi confirmada a presenca de leptospiras em todos os materiais exa- minados, nǣo havendo qualquer influência da condiçăa de lavagem sobre os valores encontrados. No entanto, por ocasiåo do terceiro dia de cultivo verifica-se um índice de positividade mais elevado para o grupo de ovários lavados 14/15 (94,0\%) contra $11 / 15(74,0 \%)$ entre os ovários não lavados. Saliente-se contudo que esta aparente diferença foi destituida de significado estatístico $(0,05<p<0,10$, teste de Qui-Quadrado).

Os exames das 30 suspensōes de ovários de hamsters infectados com L. interrogans sorotipo pomona, submetidas à pesquisa direta em microscopia de campo escuro, apresentaram resultado negativo em todas as oportunidades; os resultados das técnicas que possibilitam a visualização de leptospiras através de métodos de coloraçăo (reação de imunofluorescència direla e Levaditi), confirmaram aqueles achados clínicos e dos cultivos com $100 \%$ de positividade. No entanto, as preparaçðes tratadas pela coloração argêntica de Levaditi também permitiram a ve. rificaçåo de leptospiras localizadas em diferentes estruturas dos ovários, merecendo especial destaque as constataçoes a nivel do interstício, dos vasos sangüíneos e linfáticos e principalmente o registro dos espiroquetas na altura da zona pelúcida e no interior de óvulos. A documentaçåo folográfica de tais observaçes é apresentada na Fig.1.

A Tab. 2 apresenta os resultados dos exames histológicos dos ovários de 15 hamsters experimentalmente infectados com $\mathbf{L}$. interrogans soroupo pomona, segundo a condiçăo de lavagem prévia do órgāo. A observação dos valores referidos em tal tabela revela a existência de 17 ovários caracterizados como portadores de alteraçðes estruturais, dos quais nove submetidos ao processo de lavagem e 13 órgãos isentos de alıaraços morfológicas, incluindo sete næo lavados. $O$ estudo dos 14 valores discordantes através do teste Mc Nemar demonstrou a inexistência de associaçăo estatística entre o processo utilizado para lavagem e a presença de alteraçăo estrutural no exame do ovário. (Qui-Quadrado observado = 0,072; Qui-Quadrado crítico = 3,84). Dentre os 17 materiais com presença de alteração estrutural, a morfologia de tais lesoes incluiu as manifestaços típicas de um processo inflamatório de evoluçåo aguda com hemorragias, congestāo e edema e algumas alteraçoes degenerativas como a retraçào da zona pelúcida dos folículos ovarianos.

O exame histopatológico dos ovários dos 15 animais do grupo controle não revelou a existência de qualquer tipo de lesăo microscópica.

TABELA 1

Frequencia de hamsters experimentalmente incculados com Leptosplra intorrogans sorotipo pomona, segundo a natureza dos resultedos dos cultivos dos ovários em meio de Fletcher, o momento da leitura expresso em dias a a condiçáo de lavagem prévia do órgâo. Såo Paulo, 1992.

\begin{tabular}{|c|c|c|c|c|c|c|c|c|c|}
\hline \multirow[b]{2}{*}{ das Culturas } & & \multicolumn{2}{|l|}{$S I M$} & \multicolumn{3}{|c|}{ NAO } & \multicolumn{3}{|c|}{ TOTAL } \\
\hline & 3 & 6 & 10 & 3 & 6 & 10 & 3 & 8 & 10 \\
\hline $\begin{array}{c}\text { Positivos } \\
\text { (\%) }\end{array}$ & $\begin{array}{r}14 \\
(94)\end{array}$ & $\begin{array}{r}14 \\
(94)\end{array}$ & $\begin{array}{r}15 \\
(100)\end{array}$ & $\begin{array}{r}11 \\
(74)\end{array}$ & $\begin{array}{r}14 \\
(94)\end{array}$ & $\begin{array}{r}15 \\
(100)\end{array}$ & $\begin{array}{r}25 \\
(84)\end{array}$ & $\begin{array}{r}28 \\
(94)\end{array}$ & $\begin{array}{r}30 \\
(100)\end{array}$ \\
\hline $\begin{array}{l}\text { Negativos } \\
(\%)\end{array}$ & $\begin{array}{r}01 \\
(06)\end{array}$ & $\begin{array}{r}01 \\
(06)\end{array}$ & $\begin{array}{r}0 \\
(0)\end{array}$ & $\begin{array}{r}04 \\
(26)\end{array}$ & $\begin{array}{r}01 \\
(06)\end{array}$ & $\begin{array}{r}0 \\
(0)\end{array}$ & $\begin{array}{r}05 \\
(16)\end{array}$ & $\begin{array}{r}02 \\
(06)\end{array}$ & $\begin{array}{r}0 \\
\text { (0) }\end{array}$ \\
\hline $\begin{array}{l}\text { Total } \\
(\%)\end{array}$ & $\begin{array}{r}15 \\
(100)\end{array}$ & $\begin{array}{r}15 \\
(100)\end{array}$ & $\begin{array}{r}15 \\
(100)\end{array}$ & $\begin{array}{r}15 \\
(100)\end{array}$ & $\begin{array}{r}15 \\
(100)\end{array}$ & $\begin{array}{r}15 \\
(100)\end{array}$ & $\begin{array}{r}30 \\
(1 \infty 0)\end{array}$ & $\begin{array}{r}30 \\
(100)\end{array}$ & $\begin{array}{r}30 \\
(100)\end{array}$ \\
\hline
\end{tabular}


TABELA 2

Freqüencia de ovários de hamsters experimentalmente inçculados com Leptospira Interrogans sorotipo pomona. segundo a pesquisa do alteraç̧es estruturais, através da coloraçăo de hematoxilina - eosina e a condiçáo de lavagem prévia do órgảo Sáo Paulo. 1992

\begin{tabular}{lrrr}
\hline $\begin{array}{l}\text { Lavagem } \\
\text { Alteraçós }\end{array}$ & SIM & NAO & TOTAL \\
$\begin{array}{lrrr}\text { Estruturais dos } \\
\text { Ovários }\end{array}$ & & \\
\hline Presentes & 9 & 8 & 17 \\
Ausentes & 6 & 7 & 13 \\
Total & 15 & 15 & 30 \\
\hline
\end{tabular}

\section{DISCUSSÃO}

Os resultados obtidos realçaram aspectos cuja discussão é aprescntada a seguir:

A confirmação da indução da leptospirose aguda $\mathrm{cm}$ todos os 75 animais experimentalmente infectados com sintomatologia e lesoes à necrópsia compativeis com as descriçסes de MOUTON; HOWARTH ${ }^{16}$ (1957); SANGER el al. ${ }^{19}$ (1961); ABDU; SLEIGHT ${ }^{1}$ (1965); SAPP el al. ${ }^{22}$ (1980); BADIOLA ct al. ${ }^{3}$ (1983); INGH; HARTMAN ${ }^{12}$ (1986); PASSOS et al. ${ }^{17}$ (1988), caracteriza a virulência da amostra utilizada c assegura o primeiro parâmetro assentado no delincamento da investigaçăo que foi o de estabelecer uma populaçăo de animais que tivessem um contato efetivo com o micronganismo.

O segundo resultado obtido que confirma a validade do delineamento experimental empregado foi a incxistência de sinais clínicos nos animais nåo infectados o que demonstra a qualidade das medidas adotadas no ambiente em que foi condurida a investigaçăo, com especial destaque aos aspectos ligados às instalaçðes e ao mancjo sanitário.

Os resulados apresentados na Tab. I configurando $1(0) \%$ de positividade no décimo dia de cultivo dos materiais originários dos animais experimentalmente inlectados, além de consolidirem os informes clínicos e necroscópicos, săo também muito precoces, tendo $\mathrm{cm}$ vista as constataçoes de BRUGGE; LOUW6 (1985); PASSOS et al. ${ }^{17}$ (1988) que referem a confirmaçāo da presença de leptospiras em alguns matcriais por volta de $40^{\circ}$ ao $60^{\circ}$ dia de cultivo. A constância e a precocidade dos resultados dos cultivos do presente experimento são indicadores de que a concentração de leptospiras nos materiais examinados foi muito elevada e que os cuidados adotados para o controle de contaminação foram bem succdidos.

A verificação da ausência de influência do processo de lavagem dos ovários sobre os resultados dos cultivos sugere dois caminhos. 1) As leptospiras cstavam presentes na intimidade do tecido ovariano e portanto năo foram removidas pelo procedimento de lavagem empregado; 2) as leptospiras aderiram à superfícic extema do ovário, por ocasião de sua remoçăo da cavidade abdominal e subsequentemente năo foram retiradas pelo processo de lavagem utilizado. Caso esta última situação viesse a ser verdadeira é lícito pressupor-se que nos ovários lavados deveria existir uma maior duraçăo no período de tempo nccessário para a confirmação dos cultivos, o que não foi constatado.
Os resultados dos exames diretos em microscopia de campo escuro $\mathrm{cm}$ completo desacordo aos referidos na Tab.1, salicntam a baixa sensibilidade desta técnica, o que no entanto está de acordo com as afirmaçoes de SANTA ROSA ${ }^{20}$ (1970); El.I.IS el al. ${ }^{9}$ (1986): ELI.IS; THIERMANN ${ }^{10}$ (1986) que se referem às limitaçes de tal metoxlologia. Em contraparuda, os valores obscrvados nas coloraçóes de Levaditi e na reaçăo de imunofluorescência dircta destacam a alta eficácia de tais métodos, para revelar a presença de leptospiras como referido por PHANELF" (1970) C FAINE" (1982).

Persistindo na discussão dos resultados das preparaçðes cora. das pelas técnicas de Levaditi e de imunofluorescência dircta. cumpre ser salientado que embora os dois métodos tınham tido igual sensibilidade para revelar a presença do microorganismo, a coloraçăo pelos sais de prata foi mais rica $\mathrm{cm}$ informaçðes, pois possibilitou a visualizaça do tipo de estrutura do ovário onde as leptospiras estavam localizadas (Fig. 1). Tais observaçoses reforçam a hipótese de que durante a fase de leptospiremia existe a localizaça de leptospiras na intimidade do lecido ovariano, incluindo o meterstício, a zona pelijcida e inclusive o interior dos óvulos.

Os resultados dos exames histológicos dos ovários dos ani. mais experimentalmente infectados com a demonstraço de lesões típicas de um processo inflamatório (SMITH; JONES" 1962; SANTOS ${ }^{21}, 1979$ ), com riquèa de alteraçes vasculares, estăo de acordo com as observaçoes de CRUY" (1986) que atribui ao comprometimento do endocélio vascular à causa primária das lesōes verilicadas na leptospirose aguda. Este tipo de patologia a nível do ovário pexle inclusive explicar o encontro de lesðes degencrativas com a perda de substância intracitoplasmática de ovócitos que seriam conseyiiêncla do bloqueio do aporte sangiíneo.

Dentre os valores apresencados na Tab.2, merece ser ressallada a inexistência de lestes estruturais em 13 dos 30 ovárus cxaminatos. Embrara a ausência de lesảo no exame de uma preparaçăo histologica de um ógăo nåo garanta que toxlo o órgåo esteja iscnto de alteraçðes morfológicas, o encontro de $43 \%$ dos ovários $(13 / 30) \mathrm{cm}$ tal condiçảo constitui um fato digno de nota. Este aspecto assume ainda maior importância se forem considerados os $100 \%$ de positividade para a demonsuraçăo de leptospiras segundo os cultivos e os métodos de coloraçào.

De fato, se é pouco provável que ovários com alteraçồs inflamatórias possam produzir óvulos férteis que venham a wor fecundados e finalmente transformados $\mathrm{cm}$ embrioss, nos ovários de animais infectados por leptospiras, porém lives de alteraçðes inflamatórias (portadores såo ou convalexicentes) (FAINE" 1982 ; VASCONCELLOS ${ }^{2 k}$, 1987) toma-se muito provável a hipótese de serem observados embriơs infectados por leptospiras.

Persistindo na discussão da Tab.2, cabe ainda ser rescallada a constataçåo da inexistência de significado estatístico entre a ocorrência de alteraçð̌es estruturais c o proxesso de lavagem a que os ovários foram submetidos. Tal resultado fundamenta a afirmaçăo de que as alteraçðes estruturais em $30 \%$ (9/30) dos casos năo poderiam ser entendidas como artefatos de técnica decorrentes do processo de lavagem utilizado. 


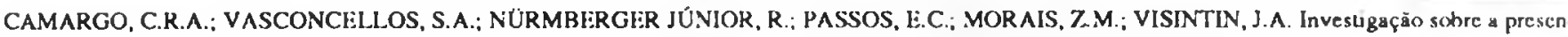
ça de leptospiras nos ovários de hamsters experimentalmente infectados con Leptospiras interrogans sorotipo pomona. Braz.. J. vet. Res. anim. Sci., Säo Paulo, v. 30, n. 2, p. 129-35, 1993.

\section{CONCLUSÕES}

Nas condiçðes em que o presente estudo foi realizado foi possivel a obtenção das seguintes conclusðes:

1. Nos ovários de hamsters experimentalmente infectados por L. interrogans sorotipo pomona foi confirmada a presença de leptospiras tanto a nível de interstício como também na zona pelúcida e no interior dos óvulos;

2. as leptospiras presentes nos ovários de hamsters experimentalmente infectados por $\mathbf{L}$. interrogans sorolipo pomona não foram removidas auravés de três lavagens sucessivas em soluçăo salina com 15 minutos de duraçăo;

3. apenas uma parcela dos ovários de hamsters experimentalmente infectados com $\mathbf{L}$. interrogans sorotipo pomona apresentou alteraçðes estruturais típicas de um processo inflamatório agudo.

\section{SUMMARY}

After inoculating $L$. interrogans serovar pomona in 75 primiparous hamsters (Mesocricetus auratus), the invasiveness of leptospires into the ovaries and the ability in causing ovary morphologic alterations were investigated by means of microscopic examination and bacterial isolation. For this purpose, 75 hamsters were inoculated with $0.5 \mathrm{ml}$ of virulent strain containing $30-40$ leptospires by the microscopic field and the other 15 hamsters were held as the uninfected controls. Signs and symptoms (prostration, tachypnea, rufled hair, jaundice, and nasal, bucal and perineal hemorrage) were detected in all inoculated animals. The animals were killed in the agonic state of the illness, which were done through $4^{\text {th }}$ and $7^{\text {th }}$ day post inoculation. The ovaries were taken asscptically during the necropsies, thoroughly washed using the sterile phosphate buffered saline, in order to eliminate the possible extemal contamination. The fresh ovary samples were submitted to the dark field direct microscopic examination. After the formalin fixation, the specimens were stained by means of histopathologic techniques using the Levaditi and Hematoxylin Eosin stains. The ovary smears were also examined by the direct fluorescent antibody technique and the bacterial isolation was carried out in the Fletcher's medium. The dark field direct microscopic examination was found to be less sensitive in demonstrating the presence of leptospires in the ovaries. In those specimens stained by the Levaditi technique, leptospires were visualized in different ovary internal structures, involving the interspace, pellucid zone and in the inner ovules. Through the histopathologic examination, typical morphologic alterations resembling acute inflamatory process were found in $57 \%$ of ovaries examined.

UNITERMS: Leptospirosis; Leptospira interrogans, isolation; Ovaries, hamsters

\section{REFERÊNCIAS BIBLIOGRÁFICAS}

01 -ABDU. M.T.F.; SLEIGTH, S.D. Pathology of experimental Leptospira pomona infection in hamsters. Cornell Vet., v.55, p.74-86, 1965.
02-ALEXANDER, A.D.; LESSEL, E.F.; EVANS, L.B.; FRANCK, E.; GREEN, S.S. Preservation of leptospiras by liquid-nitrogen refrigeration. Int. J. syst. Bacteriol., v.22, p. 165-9, 1972

03-BADIOLA, J.; THIERMANN, A.B.; CHEVELLE. N.F Pathologic features of leptospiroses in hamsters caused by Leptospira interrogans serovar hardjo ans szwayizak. Amer. J. vet. Res., v.44, p.91-9, 1983.

04-BEHMER, ().A.; TOLOSA, E.M.C.; FREITAS NETO, A.C Manual de técnicas para histologia normal e patológica. São Paulo, EdaruEDUSP, 1976.

05-BLOOD, D.C.; HENDERSON, J.A.; RODOSTITS, O.M. Clínica veterinária. S.ed. Rio de Janeiro, Guanabara Koogan. 1983. p.554-63.

06-BRUGGE, L.A.T.; LOUW, H.N. Adudition of rabbit serum to EMJH medium improves isolation of Leptospira interrogans serovar hardjo. Onderstepoort J. vet. Res., v.52, p.53-4, 1985.

07-CHEN SHISONG; WRATHALL. A.E. The imporlance of the zona pellucida for discase control in livestock by embryo transfer. Brit. vet. J., v.145, p. $129-40,1989$

08-CRUZ, J.B. Leptospirose nos animais. In: ENCONTRO NACIONAL EM LEPTOSPIROSE, 1., Salvador, 1986. Anais. p.41-3.

09.ELLIS, W.A.; MCPARLAND, P.J.; BRYSON, D.G.; THIERMANN, A.B.; MONTGOMERY, J. Isolation of leptospires from the genital tracts and kidneys of aborkd sows. Vet. Rec., v.118. p.294-5, 1986.

10-ELLIS, W.A.; THIERMANN, A.B. Isolation of leplospires from the genital tracts of lowa cows. Amer. J. vet. Res., v.47. p.1694-6, 1986.

11-FAINE, S. Guidelines for the control of kptoxpirosis. Geneva, World Health Organiyation, 1982. (Who Offset Publications, 67)

12-INGH. T.S.G.A.M. ven den; HARTMAN, E.G. Pathology of agute Leptospira interrogans serolype icterohaemorrhagiae infection in the syriam hamsters. Vet. Microbiol., v.12, p.367-76, 1986 .

13.KIKTENKO, V.S.; BALASHOW, N.G.; RODINA, V.N. Leplospirosis infection through insemination of animals. J. Hyg. Epidemiol. Microbiol. Immunol.. v.20, p.207-13. 1976.

14 McMANUS. J.F.A.; MOWRY, R.W. Staining methods: histologic and histochemical. New York, Harper \& Row, 1965.

15-MARPLETOFT, R.J. Embryo transfer and genetic engeneering. In: MORROW. D.A. Current therapy in theriogenology. 2.ed. Philadelphia, W.B. Saunders, 1986. p.51-8.

16-MOUTON. J.E.; HOWARTH. J.A. The demonstration of Leptospira canicola in hamsters kidneys by means of fluorescent antibody. Cornell Vet., v.47, p.524-32, 1957.

17-PASSOS, E.C.; VASCONCELLOS, S.A.; ITO, F.H.; YASUDA. P.H.; NURMBERGER JUNIOR, R. Isolamento de leplospiras a partir de tecido renal de hamsters experimentalmente infectados com Leptospirus Interrogans sorotipo pomona. Rev. Fac. Med. Vet. Zootec. Univ. S. Paulo, v.25, p.221-35, 1988.

18-PHANEUF, J.B. Leptospirose el léssions rénales chę le porc. Inf. Vet., v.12, p.1 104, 1970

19-SANGER, V.L.; HAMDY. A.H.; FIYETTE. W.B.; BOHL, E.H.; FERGUSON, L.C. Leptospira pomonu infection in ham. sters. Cornell Vet., v.51, p.489-98, 1961.

20-SANTA ROSA, C.A. Diagnóstico laboratorial das leptospiroses. Rev. Microblol., São Paulo, V.1, p. 97-109, 1970.

21 -SANTOS, J.A. Patología geral dos animals domésticos. Rio de Janeiro, Inter americana, 1979. 
22-SAPP, W.l.; SIDDIQUE, I.H.; WILLIANS, C.S.; GRAHAN, T. Histopathologic evolution of livers of pregnant hamsters infectod with Leptoxpira canionla Amer. J. vet. Rex, v.41, p.1288-92, 1980.

23-SIEGEL. S. Estatística nāo paramétrica para as cléncias do comportumento. São Paulo, Mc Graw Hill, 1981.

24-SLEIGHT, S.D.; WILLIAMS, J.A. Transmission of bovine leptospirosis by coition and artificial insemination. J. Amer. Vet. Med. Ass., v.138, p.151-2.1961.
25-SMITH, N.A.; JONES, T.C. Patologia veterinária. México, D.F., Union Tipografica Editorial Hispano Americana. 1962 .

26.VASCONCELLOS, S.A. O papel dos reservatórios na manutenfão de leptospirose na natureza. Comun. cient. Fac. Med. Vet. Zootec. Univ. S. Paulo, v.11. p.17-24. 1987.

Recebido para publicaçào em 01/07/92 A provado para publicaçảo em $02 / 07 / 93$ 
CAMARGO. C.R.A.; VASCONCELL.OS, S.A.; NÜRMBERGER JÚNIOR, R.; PASSOS, E.C.: MORAIS. Z.M.; VISINIIN. J.A. Imvestigação sobre a presença de leptospiras nos ovários de hamsters experimentalmente inlectados com Leptospiras interrogans sorotipo pomona. Braz.. J. vet. Res. anim. Sci.. São Paulo, v. 30, n. 2, p. 129-35, 1993.

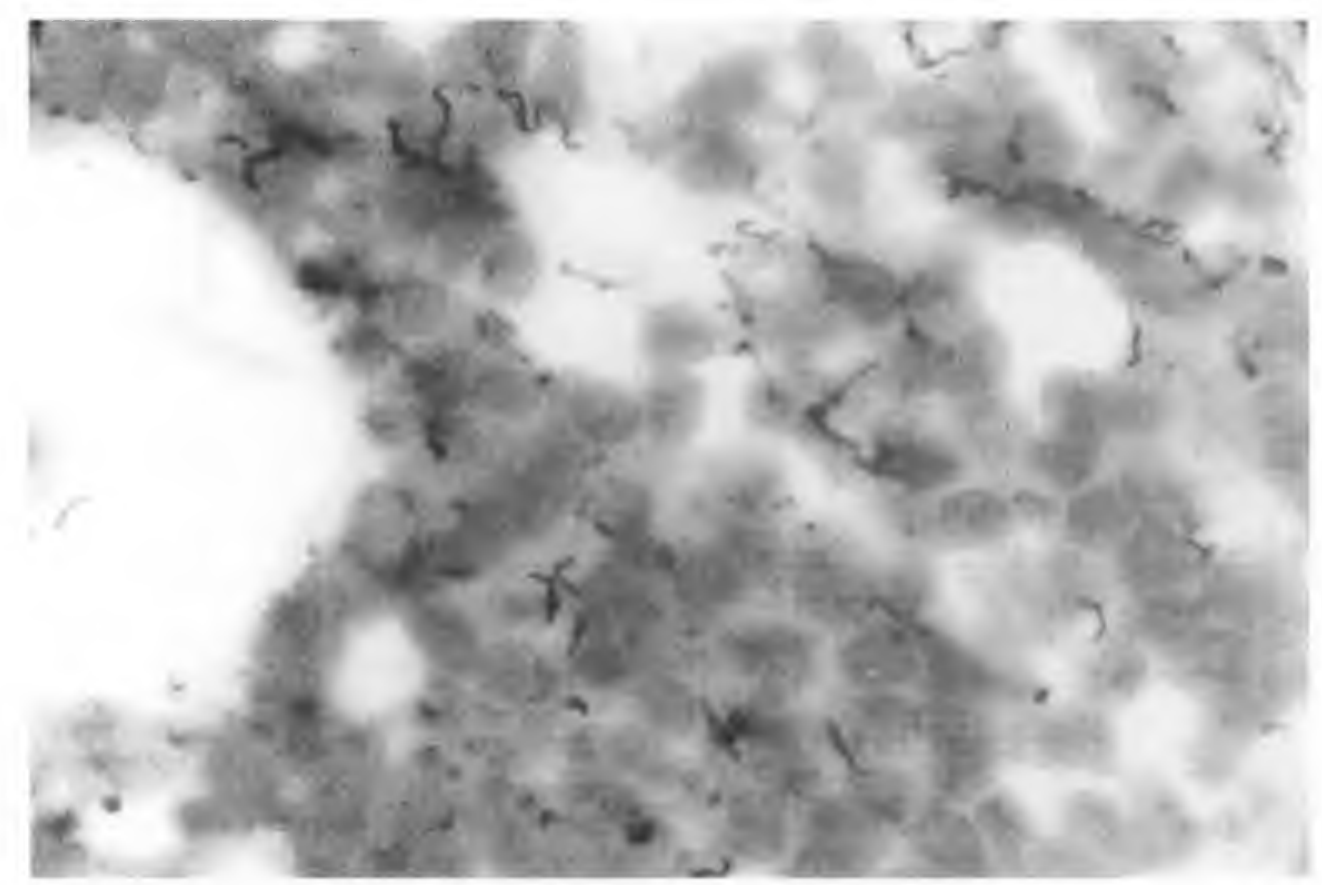

FIGURA !

Intomicrografia de ovário de hamster corado pela Técnica de Levaditi (aumentado originalmente em 1650 vezes). Microscópio ()limpus BH2. 